\title{
Coordination Mechanism of Dual-Channel Supply Chains Considering Retailer Innovation Inputs
}

\author{
Wensheng Yang ${ }^{1}$, Yinyuan Si ${ }^{1}$, Jinxing Zhang ${ }^{2}$, Sen Liu ${ }^{2, *}$ and Andrea Appolloni ${ }^{3,4,5,6, * \mathbb{D}}$ \\ 1 School of Economics and Management, Nanjing University of Science \& Technology, Nanjing 210094, China; \\ Wensheng_yang@njust.edu.cn (W.Y.); siyinyuan@njust.edu.cn (Y.S.) \\ 2 School of Logistics, Yunnan University of Finance and Economics, Kunming 650221, China; \\ zhang_jinxing1997@163.com \\ 3 Department of Management and Law, University of Rome Tor Vergata, 00133 Rome, Italy \\ 4 Institute for Research on Innovation and Services for Development (IRISS), National Research Council (CNR), \\ 80134 Naples, Italy \\ 5 School of Management, Cranfield University, Cranfield, Bedford MK43 0AL, UK \\ 6 Institute of Management, Scuola Superiore Sant'Anna, 56127 Pisa, Italy \\ * Correspondence: liusencool@ynufe.edu.cn (S.L.); andrea.appolloni@uniroma2.it (A.A.)
}

\section{check for}

updates

Citation: Yang, W.; Si, Y.; Zhang, J.; Liu, S.; Appolloni, A. Coordination Mechanism of Dual-Channel Supply Chains Considering Retailer Innovation Inputs. Sustainability 2021, 13, 813. https://doi.org/10.3390/ su13020813

Received: 28 November 2020

Accepted: 4 January 2021

Published: 15 January 2021

Publisher's Note: MDPI stays neutral with regard to jurisdictional claims in published maps and institutional affiliations.

Copyright: (c) 2021 by the authors. Licensee MDPI, Basel, Switzerland. This article is an open access article distributed under the terms and conditions of the Creative Commons Attribution (CC BY) license (https:// creativecommons.org/licenses/by/ $4.0 /)$.

\begin{abstract}
In response to the online channels established by manufacturers, physical retailers are starting to offer innovative services, which will intensify conflicts between manufacturers and retailers. Considering that the conflict will affect the operation efficiency and sustainable development of the supply chain, the coordination mechanism of a dual-channel supply chain has been established. In this study, we construct the Stackelberg game model based on consumer utility theory to analyze the complex mechanism of retailers' innovation input level affecting supply chain operation and design the double coordination mechanism. The results show that: (1) an optimal combination of wholesale prices, retail prices and innovation input levels can optimize the operational efficiency of the supply chain, (2) Noncooperation among channel members affects the retailer's product pricing, decreases the market share of the physical channel and increases the market demand of manufacturers, (3) The dual coordination mechanism can alleviate channel conflicts, which can improve the operational efficiency of the supply chain. This study provides several insights on the theory of organizational coordination and sustainable development in conflicts of dual-channel supply chains.
\end{abstract}

Keywords: dual-channel supply chain; innovation inputs; spillover effects; supply chain coordination; operational efficiency; sustainable development

\section{Introduction}

Sustainable development attracts much attention from industrial and academic communities [1]. The improvement of supply chain sustainability can shape a social image, which can improve firms' competitiveness [2]. More and more firms have begun to pay attention to the sustainable development of the supply chain. For example, some firms release their sustainability report where consumers can observe their sustainable operations about the implementation of reusable materials, green innovation and reduction of carbon emission. Thus, many potential consumers in the market will preferentially choose such type of firms. For this reason, many firms invest more resources in sustainable supply management (e.g., strengthening supply chain cooperation, providing innovation inputs) to identify and implement actions that can make them sustainable. Thus, firms are increasingly aware of the importance of sustainable supply chain management.

In practical operation and management, firms face several challenges when it comes to channeling supply chain. The traditional single physical channel can no longer meet this changed consumer demand [3], while the online channel can cater to individual 
consumer preferences. As a result, an increasing number of manufacturing companies are actively exploring online sales channels based on the physical channel $[4,5]$. However, there are differences between online channels and offline channels in terms of product price and service, which will lead to quite fierce channel competition and conflicts $[6,7]$. Specifically, the online channel offers obvious advantages in terms of product cost and price, which will have a great impact on the physical channel and directly affect the profit of physical retailers. In order to alleviate the competitive pressure brought by online channels, physical retailers will actively respond by taking advantage of facing consumers, and increase investment in innovations such as technology and marketing models. In this way, physical retailers can provide more product experience and services to strengthen consumers' perception of the value of products. Nevertheless, the behavior will intensify the competition between channels, which result in considerable conflict of interest between channel members [8,9]. Even worse, competition and conflict can reduce the efficiency of the supply chain, which causes loss of resources in the supply chain. Obviously, it is also detrimental to the sustainability of channel members and the supply chain [10].

The above analysis indicates that the sustainable development of supply chains has become an important research topic, which brings some challenges [11]. Based on the relevant researches of predecessors [12,13], strengthening cooperation among supply chain members, and focusing on the combination of supply chain management and sustainable development, will help enterprises to formulate scientific and reasonable pricing strategies and coordination strategies in the complex market environment. The strategies can give play to the advantages of different channels, and alleviate channel conflicts, so that channel members can benefit more from the supply chain system. More importantly, it will also help improve the efficiency and overall profitability of the supply chain. As a supply chain leader, manufacturers can design coordination mechanisms to strengthen cooperation with retailers [12], which means to incentivize retailers to take advantage of their directto-consumer orientation and to increase investment in innovations such as technology and marketing models, which mitigate price competition and conflicts of interest among channel members [14,15].

The current definition of the value of innovation inputs in reference to dual channels is vague. In this paper, innovation inputs are defined as the investment made by decision-makers for technological progress and green service [16], e.g., sustainable operations mode, green innovation and sustainable investment in internal logistics, warehousing and other modes, differentiating them from the concept of service efforts used in much of the literature [17-19]. Examples include investment in green product packaging services [2], big data analytics technology that makes personalized product recommendations, Lenovo's direct-to-customer marketing model innovation that provides personalized services, Haier's "first-class triple-net" logistics and inventory model innovation and so on [20]. To a certain extent, these innovation investments can tap into the potential needs of customers, which enables firms to survive in a highly competitive environment and achieve greater profitability [21]. More importantly, the cooperation of supply chain members in innovation can alleviate competition and conflict among channel members and strengthen cooperation and coordination among channel members, which is conducive to improving the operating efficiency of the supply chain. Ultimately, this helps optimize the profits of channel members and realize the sustainable development of the supply chain [22,23].

Retailers provide consumers with personalized, specialized, green and other services that rely on innovation investment. At the same time, the services brought about by the retailer's innovation inputs have a spillover effect [17], creating a free rider phenomenon in online channels based on the retailer's innovative services. Through this process, innovative services are mainly provided by physical retailers, which are to some extent included in commodity experience stores. However, online channels can also leverage high levels of innovation from brick-and-mortar physical retailers to increase demand [24]. Based on the practical problems of the above analysis, this study introduces the retailer's innovation inputs and spillover effects brought about by innovation into channel research. Then, we 
extend the consumer demand function and construct the cooperative and noncooperative supply chain Stackelberg game model based on consumer utility theory. By driving equilibrium outcomes under these scenarios, we identify the action mechanisms of spillover effects and innovation inputs on channel pricing, channel competition and profit. Finally, we design a cooperative mechanism designed to enhance the operational efficiency of the dual-channel supply chain.

This paper makes two main contributions to the literature:

(i) We pose research questions based on consumers' "offline experience, online purchase" shopping experiences in their daily lives. On this basis, we discuss the impact of retailers' innovation inputs on channel members' profitability and supply chain collaboration coordination from the perspective of innovation input spillover effects. The innovation inputs mentioned here refer to the retailer's investment in emerging technologies, marketing models, internal logistics, warehousing, etc., which empowers the retailer to provide innovative services designed to improve channel profitability and enhance supply chain operational efficiency. Ultimately, such services help supply chains achieve sustainable development and fundamentally differ from traditional promotional services such as simple product displays or product explanations. Such innovation inputs are often ignored by scholars in existing research.

(ii) In the past, when scholars studied the coordination and conflicts of dual-channel supply chains, they mostly focused on single cost-sharing contracts, revenue-sharing contracts, etc. Unlike these studies, we designed dual coordination contracts for channel conflicts. Under the contract, the manufacturer and retailer share innovation inputs, while the retailer also gives the manufacturer a share of the profits due to the increased revenue from innovation inputs. Under this dual coordination mechanism, the cost-sharing ratio has a greater range of adjustment, and the contractual options between manufacturers and retailers are more flexible. In addition, this coordination mechanism offers greater advantages in mitigating supply chain channel conflicts and improving the operational efficiency of the dual-channel supply chain.

The rest of the article is structured as follows. Section 2 reviews the relevant literature. Section 3 provides a detailed description of the problem and model assumptions explored. Section 4 discusses the games of supply chain members in the uncoordinated model of the dual-channel supply chain under cooperative and noncooperative scenarios. Section 5 analyzes the supply chain coordination strategy. Conclusions and management implications are given in Section 6.

\section{Literature Review}

\subsection{Coordination in Supply Chains}

To identify new ways to mitigate the considerable impact of online channels on physical channels, we provide an in-depth analysis of the past literature on coordination and competition in the supply chain. Regarding revenue-sharing and price discount contracts, $\mathrm{Wu}$ et al. [25] considered the impact of recycling centers on third-party recyclers (TPRs) and provided insight into how a dual-channel reverse supply chain (DRSC) with a recycling center and a TPR can optimize the interests of its members under the decentralized decision mode. The authors' findings suggest that the impact of recycling centers on thirdparty recyclers can be effectively mitigated by establishing revenue-sharing contracts between recycling centers and TPRs. Recycling centers can maximize their own profits through practices such as reducing online recycling prices and increasing service levels and offline transfer prices. Ranjan and Jha [26] investigated pricing strategy and coordination mechanisms among the members of a dual channel supply chain (DCSC) and successfully achieved interchannel coordination through a surplus profit-sharing contract to achieve a win-win situation for all members of the supply chain.

Regarding the cost-sharing contract, $\mathrm{Xu}$ et al. [27] similarly examined the coordination of supply chains consisting of manufacturers and retailers selling products through offline channels and online platforms. The study found that the supply chain can be coordinated 
through wholesale pricing and cost-sharing contracts when platform capacity is high, and even when platform capacity is low, it can still be coordinated through cost-sharing contracts when delivery time sensitivity is high. Regarding the two-part tariff contract, Feng et al. [28] also found that two-part tariff and revenue-sharing contracts can successfully coordinate reverse supply chain systems and create win-win situations. To address the challenges posed by demand disruptions to supply chain (SC) systems in the context of the information age, Hosseini-Motlagh et al. [29] developed a reverse supply chain (RSC) model based on the aforementioned research and derived optimal pricing, sustainability levels and corporate social responsibility (CSR) decisions in the context of decentralized and centralized reverse supply chain demand disruptions. The study proposes a combined scheme and demonstrates the effectiveness of the scheme by using a combined two-part tariff (CTPT) contract. The results of the study show that this option would not only improve the profitability of the RSC and its members but also improve the environment.

In addition, many nonmonetary contracts are as valuable as cost- and revenue-sharing contracts in coordinating the supply chain and improving the profitability of each supply chain member. Aslani et al. [30], in their study of pricing, product greening and coordination in a dual-channel supply chain in the presence of channel disruptions, noted that transshipment contracts can also provide effective supply chain coordination.

As shown in Table 1, we summarize the existing literature regarding coordination and competition in supply chains. As seen from the table, most of the existing research on supply chain coordination has focused on interchannel coordination using a single cost-sharing contract, revenue-sharing contract, etc. However, few scholars have used dual coordination mechanisms. Li et al. [31] studied the role of coupons in pricing and channel competition under three different distribution models using bilateral revenuesharing contracts to coordinate the dual-channel supply chain and demonstrated their effectiveness. However, the authors did not integrate the two different types of contracts, nor did they include innovative services and their spillover effects. In contrast to this work, our paper devises a dual coordination mechanism for channel conflict that uses both costand revenue-sharing contracts taking into account the retailer's innovative services and their spillover effects. Under this dual coordination mechanism, the manufacturer and retailer share the cost of the service, and the retailer provides the manufacturer with a partial incentive subsidy, which incentivizes the retailer to provide innovative services, resulting in greater gains for all members of the supply chain.

Table 1. Summary of the related literature regarding coordination and competition in supply chains.

\begin{tabular}{|c|c|c|c|c|c|c|c|}
\hline \multirow{2}{*}{ Literature } & \multicolumn{7}{|c|}{ Coordination Contract } \\
\hline & Revenue Sharing & Cost-Sharing & Price Discount & Profit Sharing & Transshipment & Two-Part Tariff & Structure \\
\hline [25] & $\sqrt{ }$ & & & & & & Single \\
\hline [26] & & & & $\sqrt{ }$ & & & Single \\
\hline [27] & & $\sqrt{ }$ & $\sqrt{ }$ & & & & Single \\
\hline [28] & $\sqrt{ }$ & $v$ & & & & $\sqrt{ }$ & Single \\
\hline [29] & & & & $\sqrt{ }$ & & $\sqrt{ }$ & Single \\
\hline$[30]$ & 1 & & & & $\sqrt{ }$ & & Single \\
\hline Our study & $\sqrt{v}$ & $\sqrt{ }$ & & & & & $\begin{array}{l}\text { Dual } \\
\text { Dual }\end{array}$ \\
\hline
\end{tabular}

\subsection{Innovation Inputs in Supply Chain}

The paper is closely related to the literature on innovation inputs. In the supply chain system, in order to better meet the needs of consumers, supply chain members began to provide innovative services, which can have an impact on the decisions of supply chain members. In this case, more and more scholars begin to pay attention to supply chain innovation inputs and focus on the coordination between innovation inputs and incentive.

Regarding innovative service inputs, i.e., innovations in technology, marketing models, etc., undertaken by policy makers, Cho et al. [14] argued that retailer innovation inputs can effectively coordinate channels; Kim et al. [15] incorporated the cost of upstream supplier innovation inputs into a supply chain benefit analysis. Sankaranarayanan [32] used game 
theory to study the optimal frequency at which the monopoly enterprises would put the innovative and improved new version on the market for free when the durable goods market faced with saturation under two cycles. Gil-Molto et al. [33] conducted that R\&D subsidies can promote investment in technology research and develop with increasing technology spillover. Battistella et al. [34] explored how supply chain distribution channels improve product quality through process innovation.

In addition, regarding retailers' innovative service, Xiao et al. [35] built Stackelberg and Bertrand game models based on innovative service, and then proposed pricing strategies under channel competition. Giri and Roy [36] examined retailers' service effort level in demand function, then explored price and service decision-making problem of the dualchannel supply chain. Considering the innovative service and advertising decisions of supply chain enterprises, Song et al. [37] investigated the optimal operation and marketing decisions of channel members under noncooperative and cooperative game structures.

As shown in Table 2, the previous literature coping with online channel intrusion can be characterized by retailer innovation investment, also from the perspective of retailers implementing service efforts and sale promotion efforts. However, the research did not consider the dual channel market characteristics of price competition $[13,14,30]$, nor did they study the coordination problem of supply chains under the innovation compensation investment [33,34]. To the best of our knowledge, there is little work investigating innovation investment in dual-channel supply chains. Especially, there is a lack of literature that considers consumers' free-riding behavior and spillover effect in retailer innovation investment.

Table 2. Summary of the related literature regarding innovation inputs.

\begin{tabular}{|c|c|c|c|c|}
\hline \multirow{2}{*}{ Literature } & \multicolumn{4}{|c|}{ Type } \\
\hline & Innovation Inputs & Innovative Service & Coordination & Spillover Effects \\
\hline$\left[\begin{array}{l}{[14]} \\
{[15]}\end{array}\right.$ & $V_{V}$ & & & $V_{\mathcal{V}}$ \\
\hline $\begin{array}{l}{[32]} \\
{[33]}\end{array}$ & $V_{V}$ & & & $\gamma$ \\
\hline$[34]$ & $\sqrt{ }$ & & $\sqrt{ }$ & \\
\hline$[36]$ & & $\mathrm{v}$ & $v^{V}$ & \\
\hline [37] & & $\sqrt{ }$ & $\sqrt{ }$ & \\
\hline Uur study & $\mathrm{V}$ & & $\sqrt{ }$ & $\sqrt{ }$ \\
\hline
\end{tabular}

\subsection{Spillover Effects}

Many scholars have conducted corresponding research on the spillover effects of services. Regarding the efforts of retailers to provide services, Telser et al. [17] analyzed the spillover effects of services and pointed out that such effects inhibit the enthusiasm of retailers to provide services, thereby affecting market demand and profits. Perry et al. [18] considered the positive spillover effects of services and analyzed the problem of manufacturers incentivizing multiple homogeneous physical stores to improve service levels. Carlton et al. [38] analyzed the free-riding behavior of consumers shifting from receiving services from physical channels to purchasing products from online channels and pointed out that manufacturers can coordinate this free riding behavior by, for example, adjusting product pricing. Wu et al. [39] analyzed the information service free-riding problem among competing retailers and pointed out that free-riding behavior is not always beneficial to free riders. Through the analysis, Shin et al. [40] concluded that the intensity of price competition among retailers can be alleviated by free-riding behavior, which benefits not only those who do not provide the service but also those who do. Liu et al. [4] showed that the negative effects of hitchhiking can be effectively eliminated through cooperation and that the various members of the supply chain can work together to achieve Pareto improvements.

Regarding the efforts of manufacturers to provide services, Bernstein et al. [41] concluded that manufacturers provide services to consumers by establishing direct selling experience stores and analyzed how manufacturers' product pricing and channel members' 
earnings are affected by retailers' free-riding behavior. In terms of the specific form of services provided, services can be categorized as general and innovative services. Regarding general service inputs, i.e., promotional services provided by retailers or manufacturers, including simple product demonstrations and product presentations, a number of scholars have demonstrated their positive role in mitigating conflicts among members of the dual-channel supply chain and enhancing supply chain profitability [25].

As shown in Table 3, we summarize the existing literature on service spillover effects. Most scholars consider the free-riding effect of innovative services based on the promotional services provided by retailers or manufacturers, including simple product demonstrations and product explanations. Such past works discuss the impacts of cross-channel freeriding on channel members and even supply chains. In contrast, there is a paucity of analysis of retailers' innovation inputs through technology and models. Even fewer studies have discussed the impact of retailers' innovation input on the profitability of channel members and the coordination of supply chain cooperation from the perspective of service spillover effects.

Table 3. Summary of the related literature regarding service spillover effects.

\begin{tabular}{ccccc}
\hline \multirow{2}{*}{ Literature } & \multicolumn{4}{c}{ Service Type } \\
\cline { 2 - 5 } & Retailer & Manufacturer & $\begin{array}{c}\text { General } \\
\text { Services }\end{array}$ & $\begin{array}{c}\text { Innovation } \\
\text { Inputs }\end{array}$ \\
\hline$[17]$ & $\sqrt{ }$ & $\sqrt{ }$ & \\
{$[18]$} & $\sqrt{ }$ & $\sqrt{ }$ & \\
{$[38]$} & $\sqrt{ }$ & $\sqrt{ }$ & \\
{$[39]$} & $\sqrt{ }$ & & \\
{$[40]$} & & & $\sqrt{ }$ \\
{$[41]$} & $\sqrt{ }$ & & $\sqrt{ }$ \\
Our study & $\sqrt{ }$ & & \\
\hline
\end{tabular}

\subsection{Summary}

In summary, as shown in Tables 1-3, the previous literature lacks consideration of consumers' free-riding behavior and spillover effect in retailer innovation inputs. Therefore, our model differs from previous studies in two areas: Firstly, the paper considers the retailer's innovation inputs and its spillover effect and constructs a Stackelberg game model to analyze the impact of the spillover effect, service innovation inputs and subsidy strategies on retailer channel pricing and profits and unlike the existing literature focuses on the innovation inputs in the dual-channel supply chains $[14,15,31]$. Secondly, in order to alleviate channel conflicts, which can improve the operational efficiency of the supply chain, we propose the dual coordination mechanism, which is different from the existing innovation investment research [32-34].

\section{Problem Description and Model Definition}

\subsection{Problem Description}

We consider a supply chain system composed of a leader, i.e., the manufacturer, a follower, i.e., the retailer, and a consumer, as shown in Figure 1. On the one hand, the manufacturer provides products to the retailer at wholesale price $p_{w}$, and the retailer sells the products to consumers at offline price $p_{r}$ through physical channels. On the other hand, the manufacturer actively opens online channels to directly sell its product at price $p_{e}$. Without a loss of generality, we suppose $p_{r}>p_{e}$ [42]. To respond to the impact of the online channel on the offline channel, the retailer invests in innovative inputs, which can increase the demand of the retailer channel market. Meanwhile, this has a positive spillover effect on the market demand of the online channel, which means that consumers can receive the services offered by the physical retail channel while purchasing products through the online channel. In other words, the innovation inputs provided by physical retailers can not only increase their own demand but also increase the demand for online channels. At the same 
time, to encourage the retailer to provide innovation inputs, alleviate channel conflict and improve the efficiency of channel operation, the manufacturer and retailer must cooperate, and each has a coordinated contract. The contract's action mechanisms are as follows: the manufacturer invests in the retailer's innovation inputs and shares the retailer's innovation input cost in proportion $\beta$. At the same time, the retailer compensates the manufacturer with fixed proportion $f$ to increase the manufacturer's investment enthusiasm.

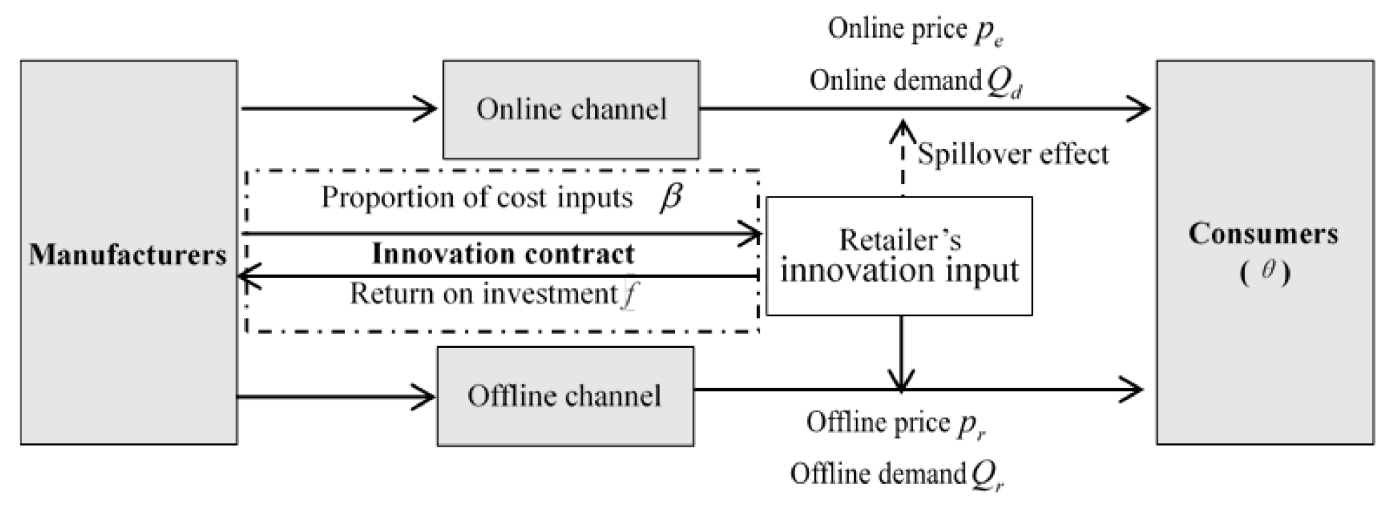

Figure 1. Dual-channel supply chain system.

\subsection{The Model}

According to the utility model developed by Chiang [6], assuming that the market size is 1 , the utility obtained from consumers purchasing products through physical channels is $U_{r}=V-p_{r}$. In addition, the consumers' valuation of product $V$ obeys a uniform distribution on $(0,1)$. The utility of consumers purchasing products through the online channel is $U_{e}=\varepsilon \theta V-p_{e}$ where $\xi(0<\xi<1)$ is the loss aversion coefficient, which depicts risk aversion behavior, which arises when the appearance or quality of the product differs from expectations [43]. Parameter $\theta(0<\theta<1)$ represents the coefficient of consumer preferences for the online channel. Consumers' basic needs are measured by the product utility function, and their purchasing decisions are determined by the utility they obtain from purchasing goods through different channels.

(1) When $U_{r}>U_{e}>0$ i.e., $V>\max \left\{p_{r}, \frac{p_{r}-p_{e}}{1-\xi^{\xi}}\right\}$, consumers buy products through the offline channel, and the basic demand of the offline channel is $Q_{r}=\int_{\max \left\{p_{r}, \frac{p_{r}-p_{e}}{1-\xi \theta}\right\}}^{1} 1 d v=$ $1-\max \left\{p_{r}, \frac{p_{r}-p_{e}}{1-\xi^{\tau} \theta}\right\}$.

(2) When $U_{e}>U_{r}>0$, i.e., $\frac{p_{e}}{\xi \theta}<V<\frac{p_{r}-p_{e}}{1-\xi^{3} \theta}$, it is clear that $p_{r}>\frac{p_{e}}{\xi \theta}$. Consumers buy products through the online channel, so basic demand for the online channel is $Q_{e}=\int_{\frac{p_{e}}{\xi \theta}}^{\frac{p_{r}-p_{e}}{1-\varepsilon \theta}} 1 d v=\frac{p_{r}-p_{e}}{1-\xi^{\xi} \theta}-\frac{p_{e}}{\xi \theta}$.

(3) When $U_{e}=U_{r}$, there is no difference in the utility of the product purchased by consumers in the two channels.

(4) When $U_{e}<0$ and $U_{r}<0$, consumers do not purchase the product and exit the marketplace.

From the above analysis, we assume that the retailer attracts consumers by improving the innovation input level, which $s(s>0)$ denotes the innovation input level factor. Thus, $\sigma s$ represents demand enhancement in the retailer channel, where $\sigma(\sigma>0)$ is the influence coefficient of innovation inputs per unit on its own demand. Meanwhile, we assume that $k s$ represents demand enhancement in the online channel where $k$ is the spillover effect coefficient on the demand. Generally, the ownership innovation investment effect is not less than the spillover effect; we thus set $0<k<\sigma$ [44]. Drawing on Zhang's analysis of cost, we assume that the cost for the retailer to provide innovation inputs is $C s=\frac{\delta s^{2}}{2}[45]$, 
where $\delta$ denotes the cost coefficient of innovation inputs [46]. Thus, the aggregate demand function expands on the basic demand to the incremental demand obtained by adding innovation inputs to the basic demand [47]. The resulting consumer demand functions for the physical and online channels are as follows:

$$
\begin{array}{r}
Q_{r}=\left\{\begin{array}{cc}
1-\frac{p_{r}-p_{e}}{1-\xi^{2} \theta}+\sigma s, & p_{r}>\frac{p_{e}}{\xi \theta} \\
1-p_{r}+\sigma s, & p_{r}<\frac{p_{e}}{\zeta \theta}
\end{array}\right. \\
Q_{e}= \begin{cases}\frac{p_{r}-p_{e}}{1-\zeta \theta}-\frac{p_{e}}{\zeta \theta}+k s, & p_{r}>\frac{p_{e}}{\zeta \theta} \\
0, & p_{r}<\frac{p_{e}}{\xi \theta}\end{cases}
\end{array}
$$

When $p_{r}<\frac{p_{e}}{\xi \theta}$, consumers will not buy products from the online channel. When $p_{r}>\frac{p_{e}}{\xi \theta}$, consumers can choose physical or online channels according to utility, which presents a dual-channel market pattern.

We summarize the notations used throughout the paper in Table 4 for ease of reference.

\begin{tabular}{|c|c|c|c|}
\hline Notation & Definition and Comments & Notation & Definition and Comments \\
\hline$p_{w}$ & the wholesale price & $\beta$ & $\begin{array}{l}\text { the proportion of innovation } \\
\text { input costs shared by } \\
\text { the manufacturer }\end{array}$ \\
\hline$p_{e}$ & the online price & $f$ & $\begin{array}{l}\text { the retailers' fixed compensation } \\
\text { to manufacturers }\end{array}$ \\
\hline$p_{r}$ & the offline price & $V$ & $\begin{array}{c}\text { the consumer's valuation of } \\
\text { the product }\end{array}$ \\
\hline$\xi$ & the loss aversion coefficient & $U_{e}$ & $\begin{array}{l}\text { the utility that consumers } \\
\text { purchasing products through } \\
\text { online channel }\end{array}$ \\
\hline$s$ & the innovative input level & $U_{r}$ & $\begin{array}{l}\text { the utility that consumers } \\
\text { purchasing products through } \\
\text { physical channel }\end{array}$ \\
\hline$k$ & the coefficient of spillover effect & $\theta$ & $\begin{array}{l}\text { the coefficient of consumer } \\
\text { preference for the online channel }\end{array}$ \\
\hline$\Pi_{i}$ & the supply channel enterprises' profit & $\delta$ & $\begin{array}{l}\text { the cost coefficient of the } \\
\text { innovative input }\end{array}$ \\
\hline$\Pi$ & the total profit of supply channel & $\sigma$ & $\begin{array}{l}\text { the coefficient of unit innovation } \\
\text { input on demand }\end{array}$ \\
\hline
\end{tabular}

Table 4. Notations list of this paper.

\section{Model Construction and Analysis}

\subsection{Cooperative Decision-Making Model}

In the cooperative decision-making model, the manufacturer and retailer form the system in which both aim to maximize the overall profit of the system. Based on the description above, the manufacturer, together with the retailer, optimizes innovation input level $\left(s^{c}\right)$, product price $\left(p_{r}^{c}\right)$ in the physical channel and product price $\left(p_{e}^{c}\right)$ in the online channel. We use superscript ' $C$ ' to describe the coordination scenario. Without a loss of generality, we assume that the manufacturer's production cost $c$ is zero so that the total profit of the dual-channel supply chain is:

$$
\prod^{c}=p_{r}^{c} Q_{r}+p_{e}^{c} Q_{e}-C\left(s^{c}\right)=p_{r}^{c}\left(1-\frac{p_{r}^{c}-p_{e}^{c}}{1-\xi^{\xi} \theta}+\sigma s^{c}\right)+p_{e}^{c}\left(\frac{p_{r}^{c}-p_{e}^{c}}{1-\xi^{\tau} \theta}-\frac{p_{e}^{c}}{\xi \theta}+k s^{c}\right)-\frac{\delta s^{c 2}}{2}
$$

Proposition 1. When the retailer provides innovation inputs, the optimal decision is $p_{r}^{c *}$ and $\mathrm{s}^{\mathrm{c} *}$ while the manufacturer's optimal decision is $p_{e}^{c *}$ and the optimal supply chain return is $\prod^{\mathrm{c} *}$. 


$$
\left\{\begin{array}{l}
p_{r}^{c *}=\frac{2 \delta-k^{2} \theta \xi(1-\theta \xi)}{2\left(2 \delta-k^{2} \theta \xi-2 k \theta \xi \sigma-\sigma^{2}\right)} \\
\mathrm{s}^{\mathrm{c} *}=\frac{k \theta \xi+\sigma}{2 \delta-k^{2} \theta \xi-2 k \theta \xi \sigma-\sigma^{2}} \\
p_{e}^{c *}=\frac{\theta \xi}{2}-\frac{\theta \xi(k+\sigma)(k \theta \xi+\sigma)}{2\left(k^{2} \theta \xi+2 k \theta \xi \sigma+\sigma^{2}-2 \delta\right)} \\
\Pi^{\mathcal{*}}=\frac{\theta \xi\left[-2 \delta+k^{2} \theta \xi(1-\theta \xi)\right]}{4 \theta \xi\left(k^{2} \theta \xi+2 k \theta \xi \sigma+\sigma^{2}-2 \delta\right)}
\end{array}\right.
$$

Proof. See Appendix A.

Further, by analyzing the conclusions of the centralized decision condition, we make the following proposition.

Proposition 2. The stronger the consumer's preference for the online channel, the lower the offline price $\left(p_{r}^{c}\right)$ is and the higher the online price $\left(p_{e}^{c}\right)$ is.

Proof. Based on the retailer's and manufacturer's optimal decisions, the first-order conditions are given by:

(i) $\frac{d p_{r}^{c *}}{d \theta}=-\frac{k \xi(k \theta \xi+\sigma)\{k[\theta \xi(k+2 \sigma)-\sigma]-4 \delta\}}{2\left(k^{2} \theta \xi+2 k \theta \xi \sigma+\sigma^{2}-2 \delta\right)^{2}}$ due to $p_{r}>\frac{p_{e}}{\varepsilon \theta}$; we can infer that $k \theta \xi<\sigma$ and $k^{2} \theta \xi+2 k \theta \xi \sigma+\sigma^{2}<2 \delta$. Obviously, we have $\frac{d p_{r}^{c *}}{d \theta}<0$.

(ii) $\frac{d p_{e}^{c *}}{d \theta}=\frac{\xi}{2} \frac{4 \delta^{2}-2 \delta \sigma[k(2 \theta \xi-1)+\sigma]+k \sigma(k \theta \xi+\sigma)[\theta \xi(k+2 \sigma)-\sigma]}{\left(k^{2} \theta \xi+2 k \theta \xi \sigma+\sigma^{2}-2 \delta\right)^{2}}$ due to $p_{r}>\frac{p_{e}}{\varepsilon \theta}$; we can infer that $k \theta \xi<\sigma$ and $k^{2} \theta \xi+2 k \theta \xi \sigma+\sigma^{2}<2 \delta$. Obviously, we have $\frac{d p_{e}^{c *}}{d \theta}>0$.

Proposition 3. The level of innovation inputs $\left(s^{c}\right)$ provided by the retailer increases as consumers' preferences for online channels $(\theta)$ increase and as the spillover effect $(k)$ of innovation inputs increases.

Proof. Based on the retailer's and manufacturer's optimal decisions, the first-order conditions are given by:

(i) $\frac{d s^{c *}}{d \theta}=\frac{k \xi(2 \delta+\sigma(k+\sigma))}{\left(k^{2} \theta \xi+2 k \theta \xi \sigma+\sigma^{2}-2 \delta\right)^{2}}$; because parameters $k, \xi, \delta, \theta$ in the model are greater than zero, it is obvious that we have $\frac{d s^{c *}}{d \theta}>0$.

(ii) $\frac{d s^{c *}}{d k}=\frac{\theta \xi\left(2 \delta+k^{2} \theta \xi+2 k \sigma+\sigma^{2}\right)}{\left(k^{2} \theta \xi+2 k \theta \xi \sigma+\sigma^{2}-2 \delta\right)^{2}}$, and in the same we have $\frac{d c^{*}}{d k}>0$.

The above analysis shows that the degree of consumer preference for the online channel and the spillover effect of the innovation inputs offered by retailers will affect the retailer's product pricing and the level of innovation inputs as well as having a strong impact on product pricing for the online channel. As the number of consumers who prefer online channels increases, retailers will lower the price of their products to expand demand through the price advantage. At the same time, innovation services provided by retailers have a spillover effect, which stimulates retailers to extend their innovation services and increase supply chain revenues.

Proposition 4. The higher the level of innovation inputs offered by the retailer, the higher the retailer's product pricing is and the higher the product pricing of the online channel is. However, the total supply chain's profit is a convex function of the level of innovation inputs.

Proof. We obtain the functional relations of $s^{c}$ with $p_{r}^{c}, p_{e}^{c}$ and $\prod^{c}$ by backward induction and by first-order conditions as follows $p_{r}^{c}=\frac{1}{2}\left(1+k s^{c} \theta \xi+s^{c} \sigma\right), p_{e}^{c}=\frac{\theta \xi}{2}\left[1+s^{c}(k+\sigma)\right]$, $\Pi^{c *}=\frac{1+2 s(k \theta \xi+\sigma)+s^{2}\left(k^{2} \theta \xi+2 k \theta \xi \sigma+\sigma^{2}-2 \delta\right)}{4}$. 
(i) From $\frac{d p_{e}^{c}}{d s}=\frac{1}{2} \theta \xi(k+\sigma)>0, \frac{d p_{e}^{c}}{d s}=\frac{1}{2}(k \theta \xi+\sigma)>0$ it is clear that the higher the level of innovation services offered by the retailer, the higher the retailer's product pricing and online channel product pricing become.

(ii) From $\frac{d \prod^{2} 2}{d s^{2}}=\frac{1}{2}\left(k^{2} \theta \xi+2 k \theta \xi \sigma+\sigma^{2}-2 \delta\right)<0$, the total profit of the supply chain is a convex function with the level of innovation services. When the retailer reduces the level of innovation services provided, the retailer's costs will decrease, which means that the total profit of the supply chain will increase. Conversely, when the level of innovation service increases, the increased costs borne by the retailer outweigh the benefits of innovation. Thus, the total profit of the supply chain will in turn decrease.

Proposition 4 indicates that the level of innovation inputs offered by the retailer has an impact on the retailer's product pricing and online channel product pricing. The retailer will inevitably incur higher costs if increasing the level of innovation inputs, including targeted advertising, conducting professional explanatory services, experiencing products, offering free trials and convenient logistics. When the increase in the cost of innovation inputs is less than the increase in corresponding benefits, the total profit of the supply chain will increase. Conversely, when the level of innovation inputs increases, the increase in the cost borne by the retailer is greater than the benefit brought by innovation. Thus, the total profit of the supply chain will decrease. Based on the description above, the retailer and manufacturer will aim to avoid a reduction in the total profitability of the supply chain by increasing the prices of their products.

\subsection{Noncooperative Decision-Making Model}

Under the noncooperative decision mode, we model the decision process as a sequential Stackelberg game with the manufacturer as the leader and the retailer as the follower, which make their own decisions to maximize their individual profits. The duopoly Stackelberg game decision process is assumed to follow the following sequence: the manufacturer determines $p_{w}^{D}$ and $p_{e}^{D}$ first. After receiving the manufacturer's decision information, the retailer determines $p_{r}^{D}$ and $s^{D}$. We use superscript " $\mathrm{D}$ " to describe the noncooperative decision scenario. Then, the manufacturer and retailer's profit functions are:

$$
\left\{\begin{array}{c}
\prod_{m}^{D}=p_{w}^{D}\left(1-\frac{p_{r}^{D}-p_{w}^{D}}{1-\varepsilon \theta}+\sigma s^{D}\right)+p_{e}^{D}\left(\frac{p_{r}^{D}-p_{w}^{D}}{1-\varepsilon \theta}-\frac{p_{e}^{D}}{\varepsilon \theta}+k s^{D}\right) \\
\prod_{r}^{D}=\left(p_{r}^{D}-p_{w}^{D}\right)\left(1-\frac{p_{r}^{D}-p_{w}^{D}}{1-\varepsilon \theta}+\sigma s^{D}\right)-\frac{\delta s^{D^{2}}}{2}
\end{array}\right.
$$

In solving the first-order conditions, we obtain the equilibrium solution. The results are summarized in Proposition 5.

Proposition 5. An optimal combination strategy for price and innovation input levels can optimize supply chain profits and achieve equilibrium.

$$
\begin{aligned}
& \left\{\begin{array}{c}
p_{w}^{D *}=\frac{4 \delta^{2}-k \theta \xi \sigma^{2}(\theta \xi-1)^{2}(k+\sigma)+\sigma \delta(\theta \xi-1)[2 \sigma+\theta \xi(k+\sigma)]}{8 \delta^{2}+4 \delta \sigma^{2}(\theta \xi-1)+\theta \xi \sigma^{2}(\theta \xi-1)(k+\sigma)^{2}} \\
p_{e}^{D *}=\frac{\delta \theta \xi[4 \delta-\sigma(\theta \xi-1)(k-\sigma)]}{8 \delta^{2}+4 \delta \sigma^{2}(\theta \xi-1)+\theta \xi \sigma^{2}(\theta \xi-1)(k+\sigma)^{2}}
\end{array}\right. \\
& \left\{\begin{array}{c}
p_{r}^{D *}=\frac{\delta^{2}(6-2 \theta \xi)+2 \delta \sigma^{2}(\theta \xi-1)-k \theta \xi \sigma^{2}(\theta \xi-1)^{2}(k+\sigma)}{8 \delta^{2}+4 \delta \sigma^{2}(\theta \xi-1)+\theta \xi \sigma^{2}(\theta \xi-1)(k+\sigma)^{2}} \\
s^{D *}=\frac{\sigma(1-\theta \xi)[2 \delta+\theta \xi \sigma(k+\sigma)]}{8 \delta^{2}+4 \delta \sigma^{2}(\theta \xi-1)+\theta \xi \sigma^{2}(\theta \xi-1)(k+\sigma)^{2}}
\end{array}\right.
\end{aligned}
$$


By substituting Equations (6) and (7) into Equation (5), we have Equation (8):

$$
\left\{\begin{array}{c}
\prod_{m}^{D *}=\frac{\delta[\delta+\delta \theta \xi+k \theta \xi \sigma(1-\theta \xi)]}{8 \delta^{2}+4 \delta \sigma^{2}(\theta \xi-1)+\theta \xi \sigma^{2}(\theta \xi-1)(k+\sigma)^{2}} \\
\prod_{r}^{D *}=\frac{\delta(1-\theta \xi)\left[2 \delta+\sigma^{2}(\theta \xi-1)\right][2 \delta+\theta \xi \sigma(k+\sigma)]^{2}}{2\left[8 \delta^{2}+4 \delta \sigma^{2}(\theta \xi-1)+\theta \xi \sigma^{2}(\theta \xi-1)(k+\sigma)^{2}\right]^{2}} \\
\prod^{D}=\frac{\delta\left\{(1-\theta \xi)\left[2 \delta+\sigma^{2}(\theta \xi-1)\right][2 \delta+\theta \xi \sigma(k+\sigma)]^{2}+2 \Gamma_{1} \Gamma_{2}\right\}}{2\left[8 \delta^{2}+4 \delta \sigma^{2}(\theta \xi-1)+\theta \xi \sigma^{2}(\theta \xi-1)(k+\sigma)^{2}\right]^{2}}
\end{array}\right.
$$

where $\Gamma_{1}=\delta+\delta \theta \xi+\sigma k \theta \xi(1-\theta \xi), \Gamma_{2}=8 \delta^{2}+4 \delta \sigma^{2}(\theta \xi-1)+\theta \xi \sigma^{2}(\theta \xi-1)(k+\sigma)^{2}$.

Proof. See Appendix B.

When manufacturer and retailer pricing and innovation input levels meet Equations (6) and (7), profit optimization can be implemented, and Stackelberg game equilibrium can be achieved.

Proposition 6. The retailer's product pricing $\left(p_{r}^{D}\right)$, wholesale price $\left(p_{w}^{D}\right)$ and online channel product pricing $\left(p_{e}^{D}\right)$ will increase as the level of innovation services increases. In addition, the magnitude of their increase will increase as spillover effect $k$ increases.

Proof. We obtain the innovation input level as a function of physical channel product pricing $\left(p_{r}^{D *}\right)$, wholesale pricing $\left(p_{w}^{D *}\right)$ and online channel product pricing $\left(p_{e}^{D *}\right)$ by backward induction and first-order conditions, i.e., $p_{r}^{D *}=\frac{3+3 s \sigma+\theta \xi(2 k s-1+s \sigma)}{4}, p_{w}^{D *}=\frac{1+k s \theta \xi+s \sigma}{2}$, $p_{e}^{D *}=\frac{\theta \xi[1+s(k+\sigma)]}{2}$. We conduct further analyses and find the following.

(i) $\frac{d p_{r}^{D *}}{d s^{D}}=\frac{1}{4}[2 k \theta \xi+(3-\theta \xi) \sigma]>0$, and thus $p_{r}^{D}$ increases as $s^{D}$ increases. Then, from $\frac{d p_{r}^{D *}}{d s^{D} d k}=\frac{\theta \xi}{2}>0, p_{r}^{D}$ increases to the extent that spillover effect $k$ increases.

(ii) $\frac{d p_{e}^{D *}}{d s^{D}}=\frac{1}{2} \theta \xi(k+\sigma)>0$, and thus as $s^{D}$ increases, $p_{e}^{D}$ also increases. Then, from $\frac{d p_{e}^{D *}}{d s^{D} d k}=\frac{\theta \xi}{2}>0$, the extent of the above increase will increase with spillover effect $k$.

(iii) $\frac{d p_{w}^{D *}}{d s^{D}}=\frac{1}{2}(k \theta \xi+\sigma)>0$, and thus as $s^{D}$ increases, $p_{w}^{D}$ also increases. From $\frac{d p_{w}^{D *}}{d s^{D} d k}=\frac{\theta \xi}{2}>0$, the extent of the increase increases with spillover effect $k$.

Proposition 6 indicates that the retailer, as an independent decision maker, must bear the full cost of innovation inputs. Therefore, it is necessary to raise the price of the product to cover the cost of innovation inputs. At the same time, the higher the spillover effect coefficient of innovation inputs on online channels is, the worse the effect of the retailer's innovation inputs becomes. Because of this, the retailer needs to continue to improve the level of innovation inputs to expand market demand, which imposes greater costs. Thus, the retailer will raise retail prices to avoid losing its revenue. Likewise, as the retailer improves its level of innovation inputs, online channels can enjoy more convenience and gain greater channel advantages, which can increase the price of online channel products and secure more revenue. More importantly, the greater the spillover effect coefficient on the online channel, the greater the advantage of the online channel. Thus, the manufacturer can afford to lose some consumers due to increased prices.

Proposition 7. The manufacturer's profit $\left(\prod_{m}^{D}\right)$ and retailer's innovation input level $\left(s^{D}\right)$ are concave functions, while the retailer's profit $\left(\Pi_{r}^{D}\right)$ and supply chain's total profit $\left(\Pi^{D}\right)$ are both convex functions with respect to the level of innovation inputs $\left(s^{D}\right)$.

Proof. We obtain the functional relations between variables $\prod_{m}^{D}, \prod_{r}^{D}, \Pi^{D}$ and $s^{D}$ by backward induction and by first-order conditions as follows: 
(i) $\frac{d \prod_{m}^{D 2}}{d s^{D 2}}=\frac{1}{4}\left(2 k^{2} \theta \xi+4 k \theta \xi \sigma+(1+\theta \xi) \sigma^{2}\right)>0$, and thus the manufacturer's profit and retailer's innovation input level are concave functions. When innovation inputs are relatively low, the retailer is in a position to earn higher profits with lower innovation input costs. Thus, the manufacturer's profits are impacted, showing a downward trend. When innovation services are at a higher level, retailers are bound to bear greater costs, which puts them at a disadvantage. However, in this case, manufacturers will obtain a stronger spillover effect from innovation services, so profits will inevitably increase.

(ii) $\frac{d \prod_{r}^{D 2}}{d s^{D 2}}=-\delta-\frac{1}{8}(-1+\theta \xi) \sigma^{2}<0$, and thus the retailer's profit exhibits a convex functional relationship with innovation inputs. When $s$ satisfies $0<s<\frac{\sigma-\theta \xi \sigma}{8 \delta-(\mathbf{1}-\theta \xi) \sigma^{2}}$, the cost of innovation inputs increases exponentially. When innovation inputs are low, the cost is low. Because the incremental revenue brought by innovation inputs is greater than the innovation input cost, the retailer's profit increases with the increase in innovation services. Likewise, when $s$ satisfies $s>\frac{\sigma-\theta \xi \sigma}{8 \delta-(1-\theta \xi) \sigma^{2}}$, because the innovation input cost increases rapidly, the incremental income cannot cover the innovation input cost, which results in the retailer's profit decreasing with the increase in innovation services.

(iii) $\frac{d \prod^{D 2}}{d s^{D 2}}=\frac{1}{8}\left(-8 \delta+4 k^{2} \theta \xi+8 k \theta \xi \sigma+(3+\theta \xi) \sigma^{2}\right)<0$, and thus the total supply chain profit is a convex function with respect to innovation inputs. When $s$ satisfies $0<s<\frac{3 \sigma+\theta \xi(4 k+\sigma)}{8 \delta-4 k^{2} \theta \xi-8 k \theta \xi \sigma-(3+\theta \xi) \sigma^{2}}$, if innovation inputs are low, the increase in the retailer's profit is greater than the decrease in the manufacturer's profit, i.e., the total profit of the supply chain increases with increasing innovation inputs. Likewise, when $s$ satisfies $s>\frac{3 \sigma+\theta \xi(4 k+\sigma)}{8 \delta-4 k^{2} \theta \xi-8 k \theta \xi \sigma-(3+\theta \xi) \sigma^{2}}$, the decrease in the retailer's profit is greater than the increase in the manufacturer's profit, which indicates that the total profit of the supply chain decreases with the increase in innovation inputs.

\subsection{Equilibrium Analysis}

Corollary 1. Noncooperation among channel members affects the retailer's product price, and the retailer should dynamically adjust its pricing strategy based on consumers' preferences for online channels.

Proof. According to propositions 1 and 5, we can clearly see that $p_{r}^{D *}-p_{r}^{c *}=$ $\frac{\delta^{2}(6-2 \theta \xi)+2 \delta \sigma^{2}(\theta \xi-1)-k \theta \xi \sigma^{2}(\theta \xi-1)^{2}(k+\sigma)}{8 \delta^{2}+4 \delta \sigma^{2}(\theta \xi-1)+\theta \xi \sigma^{2}(\theta \xi-1)(k+\sigma)^{2}}-\frac{2 \delta-k^{2} \theta \xi(1-\theta \xi)}{2\left(2 \delta-\theta \xi k^{2}-2 k \theta \xi \sigma-\sigma^{2}\right)}$. Because the result is too technically complex to conduct a generality analysis, we employ numerical simulations to study the action mechanism. As the parameters are fixed, consumers' preferences for online channels may differ. Thus, we assume that $k=0.4, \sigma=0.6, \delta=2, \xi=0.8$ and focus on analyzing the influence of consumers' preferences for the online channel on price. In turn, we have Table 5.

Table 5. The comparison of retailer's product price in the two scenarios.

\begin{tabular}{cccccc}
\hline$\theta$ & $\mathbf{0 . 2}$ & $\mathbf{0 . 4}$ & $\mathbf{0 . 6}$ & $\mathbf{0 . 8}$ & $\mathbf{0 . 9}$ \\
\hline$p_{r}^{D *}-p_{r}^{c *}$ & 0.165 & 0.105 & 0.043 & -0.019 & -0.051 \\
\hline
\end{tabular}

From Table 4, we can see that the optimal offline price in the noncooperative scenario is greater than that in the cooperative scenario if the consumers' preferences for the online channel are lower. Less consumer preference indicates that consumers do not have a strong preference for the online channel. Consequently, the retailer will focus on attracting consumers by providing innovation inputs, which imposes a higher cost. Hence, the retailer can appropriately increase the retail price of their products. In contrast, when consumers' preferences for the online channel are stronger, the optimal offline price in the noncooperative scenario is lower. This indicates that consumers prefer online channels, so 
it is difficult for the retailer to attract consumers through pure innovation inputs. Therefore, the retailer can use low prices to draw consumers toward physical channels.

In general, noncooperation among channel members will affect offline prices, but the retailer can adjust pricing strategies appropriately according to consumers' online channel preferences, which is in line with reality.

Corollary 2. Compared to the equilibrium outcome of the cooperative scenario, the retailer's innovation inputs are greater under the noncooperative scenario.

Proof. According to propositions 1 and 5 , we can see that $\mathrm{s}^{\mathrm{c} *}-\mathrm{s}^{D *}=$ $-\frac{\left[\delta+(1-\theta \xi) \sigma^{2}\right]\left\{k^{2} \theta \xi(1-\theta \xi) \sigma+2 \delta(1+\theta \xi) \sigma+k \theta \xi\left[4 \delta+(1-\theta \xi) \sigma^{2}\right]\right\}}{\left(k^{2} \theta \xi+2 k \theta \xi \sigma+\sigma^{2}-2 \delta\right)\left(8 \delta^{2}+4 \delta(\theta \xi-1) \sigma^{2}+\theta \xi(\theta \xi-1) \sigma^{2}(k+\sigma)^{2}\right)}<0$. Thus, the manufacturer and retailer make decisions alone to maximize their respective profits rather than total supply chain profits in the cooperative scenario. The retailer needs to provide more innovation inputs to maximize its own profit. Consequently, the level of innovation inputs provided by the retailer in the noncooperative scenario is necessarily greater than that provided under the cooperative scenario.

From Corollary 2, we know that the cost of innovation services needs to be borne by the retailer alone and affects the retailer's incentives to a certain extent, which is not conducive to supply chain optimization. As a result, manufacturers, as the dominant channel players, must actively join the retailer and strengthen cooperation among channel members to improve the operational efficiency and profitability of the channel.

Corollary 3. Noncooperation among channel members decreases the market share of the physical channel while increasing the online market demand of the manufacturer.

Proof. From propositions 1 and 5, it is clear that $Q_{r}^{D}-Q_{r}^{C}<0, Q_{e}^{D}-Q_{e}^{D}>0$. This means that the pressure of the cost of innovation inputs causes the retailer to raise offline prices, which results in a decline in market share in the noncooperative scenario. The online channel is affected by the spillover effect brought about by the retailer's innovation inputs coupled with its certain price advantage; thus, the online channel market share will increase.

Corollary 4. Cooperation among channel members can improve the profit of the total supply chain.

Proof. $\Pi^{c *}-\Pi^{D}>0$; thus, cooperation among channel members, especially when the manufacturer joins the retailer in innovation inputs, helps attract more consumers in the cooperative scenario. However, under the noncooperative scenario, competition among channel members makes the supply chain less profitable, which is detrimental to the efficiency of the supply chain.

Corollary 4 indicates that under the noncooperative scenario, the manufacturer and retailer make decisions alone to maximize their respective profits rather than the total supply chain profit, resulting in a decline in total supply chain returns. In addition, the retailer bears the cost of innovation alone, which exacerbates channel conflict to some extent. In general, cooperation among channel members benefits the supply chain, while noncooperation harms the supply chain. Therefore, it is necessary to explore effective strategies for coordinating the dual channel to mitigate the impact of online channels on physical channels. Ultimately, this approach will improve the operational efficiency of the channel and maintain the balanced development of the dual-channel supply chain. 


\section{Supply Chain Coordination Strategy}

\subsection{Dual Coordination Strategy Model}

In reality, there is a certain amount of competition between channel members, and it is difficult to achieve a fully cooperative relationship. Competition can impair the operational efficiency of the supply chain, which in turn can affect the chain's overall profitability. Thus, this section focuses on the analysis of competition problems in noncooperative scenarios and further designs models of dual coordination strategies that can improve the efficiency of the supply chain. From the model, this study focuses on joint decision-making between the manufacturer and retailer in innovation inputs, which means that both the manufacturer and retailer share innovation input costs. At the same time, the retailer provides a transfer payment to manufacturers to incentivize the manufacturer to share costs. Thus, the manufacturer and retailer agree on a dual coordination strategy in the form of a contract $(\beta, f)$.

Specifically, the manufacturer invests in the retailer's innovation inputs and shares the retailer's cost of innovation in proportion $\beta$. Then, the retailer compensates the manufacturer with a fixed $f$ to increase the manufacturer's enthusiasm. Under the game mechanism, the manufacturer determines $p_{w}^{I}, p_{e}^{I}$ and $f$ in stage 1 . After receiving the manufacturer's decision information, the retailer determines $p_{r}^{I}, s^{I}$ and $\beta$. We use superscript " $I$ " to denote the coordination model scenario. Then, the manufacturer and retailer's profit functions are:

$$
\left\{\begin{array}{c}
\prod_{m}^{I}=p_{w}^{I}\left(1-\frac{p_{r}^{I}-p_{w}^{I}}{1-\varepsilon \theta}+\sigma s^{I}\right)+p_{e}^{I}\left(\frac{p_{r}^{I}-p_{w}^{I}}{1-\varepsilon \theta}-\frac{p_{e}^{I}}{\varepsilon \theta}+k s^{I}\right)-\frac{\beta \delta I^{2}}{2}+f \\
\prod_{r}^{I}=\left(p_{r}^{I}-p_{w}^{I}\right)\left(1-\frac{p_{r}^{I}-p_{w}^{I}}{1-\varepsilon \theta}+\sigma s^{I}\right)-\frac{(1-\beta) \delta s^{I^{2}}}{2}-f
\end{array}\right.
$$

Proposition 8. In the coordination model, the manufacturer's optimal decisions are $p_{w}^{I *}, p_{e}^{I *}$ and $\beta^{*}$, as shown in Equation (10). Meanwhile, the retailer's optimal decisions are $p_{r}^{I *}, s^{I *}$, as shown in Equation (11).

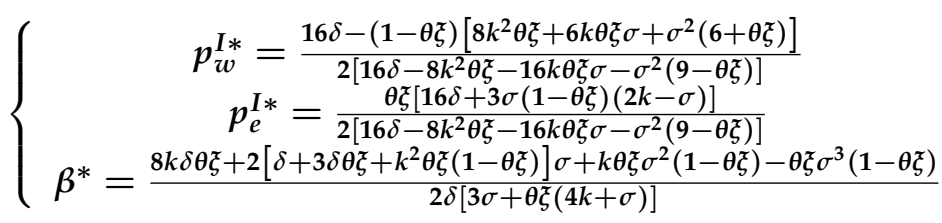

$$
\begin{aligned}
& \left\{\begin{array}{l}
p_{r}^{I *}=\frac{8 \delta(3-\theta \zeta)-(1-\theta \xi)\left[12 k^{2} \theta \zeta+8 k \theta \xi \sigma+\sigma^{2}(6-\theta \xi)\right]}{2\left[16 \delta-8 k^{2} \theta \xi-16 k \theta \xi \sigma-\sigma^{2}(9-\theta \xi)\right]} \\
s^{I *}=\frac{6 \sigma+2 \theta \zeta(4 k+\sigma)}{16 \delta-8 k^{2} \theta \zeta-16 k \theta \zeta \sigma-\sigma^{2}(9-\theta \xi)}
\end{array}\right.
\end{aligned}
$$

Proof. See Appendix B.

Proposition 9. An optimal combination strategy of price and innovation input levels can be used to optimize supply chain profits and achieve equilibrium.

$$
\left\{\begin{array}{c}
\prod_{m}^{I *}=\frac{8 \delta(1+\theta \xi)+\theta \xi(-1+\theta \xi)(-2 k+\sigma)^{2}}{4\left[16 \delta-8 k^{2} \theta \xi(16 k \theta \xi)-\sigma^{2}(9-\theta \xi)\right]}+f \\
\prod_{r}^{I *}=\frac{D(1-\theta \xi)[\theta \xi(2 k-\sigma)(k+\sigma)-4 \delta}{\left[16 \delta-8 k^{2} \theta \xi-16 k \theta \xi \sigma-\sigma^{2}(9-\theta)\right]^{2}}-f \\
\prod^{I}=\frac{8 \delta(1+\theta \xi)+\theta \xi(-1+\theta \xi)(-2 k+\sigma)^{2}}{4\left[16 \delta-8 k^{2} \theta \xi-16 k \theta \xi \sigma-\sigma^{2}(9-\theta \xi)\right]}+\frac{\Gamma_{3}(1-\theta \xi)[\theta \zeta(2 k-\sigma)(k+\sigma)-4 \delta]}{\left[16 \delta-8 k^{2} \theta \xi-16 k \theta \xi \sigma-\sigma^{2}(9-\theta \xi)\right]^{2}}
\end{array}\right.
$$

where $\Gamma_{3}=2 k^{2} \theta \xi+5 k \theta \xi \sigma+3 \sigma^{2}-4 \delta$.

Proof. See Appendix C. 
Corollary 4. Under the dual coordination strategy, there is an optimal investment compensation interval for the retailer, which increases the profits of both the retailer and manufacturer.

Proof. To achieve the optimization of the dual-channel supply chain system, it is necessary to ensure that the profits of the retailer and manufacturer are increased, i.e., the following regulatory requirements are met:

(i) From $\Delta \prod_{m}^{I *}=\prod_{m}^{I *}-\prod_{m}^{D *}>0, \quad f>\frac{\delta[\delta+\delta \theta \xi+k \theta \xi \sigma(1-\theta \xi)]}{8 \delta^{2}+4 \delta \sigma^{2}(\theta \xi-1)+\theta \xi \sigma^{2}(\theta \xi-1)(k+\sigma)^{2}}-$ $8 \delta(1+\theta \xi)+\theta \xi(-1+\theta \xi)(-2 k+\sigma)^{2}$

$\overline{4\left[16 \delta-8 k^{2} \theta \xi-16 k \theta \xi \sigma-\sigma^{2}(9-\theta \xi)\right]}$.

(ii) $\quad$ From $\Delta \prod_{r}^{I *}=\prod_{r}^{I *}-\prod_{r}^{D *}>0, \quad f<\frac{D(1-\theta \xi)[\theta \xi(2 k-\sigma)(k+\sigma)-4 \delta]}{\left[16 \delta-8 k^{2} \theta \xi-16 k \theta \xi \sigma-\sigma^{2}(9-\theta \xi)\right]^{2}}-$ $\frac{\delta(1-\theta \xi)\left[2 \delta+\sigma^{2}(\theta \xi-1)\right][2 \delta+\theta \zeta \sigma(k+\sigma)]^{2}}{2\left[8 \delta^{2}+4 \delta \sigma^{2}(\theta \xi-1)+\theta \zeta \sigma^{2}(\theta \zeta-1)(k+\sigma)^{2}\right]^{2}}$.

Thus, interval of $f$ is $(f, \bar{f})$, where

$$
\begin{gathered}
\underline{f}=\frac{\delta[\delta+\delta \theta \xi+k \theta \xi \sigma(1-\theta \xi)]}{8 \delta^{2}+4 \delta \sigma^{2}(\theta \xi-1)+\theta \xi \sigma^{2}(\theta \xi-1)(k+\sigma)^{2}}-\frac{8 \delta(1+\theta \xi)+\theta \xi(-1+\theta \xi)(-2 k+\sigma)^{2}}{4\left[16 \delta-8 k^{2} \theta \xi-16 k \theta \xi \sigma-\sigma^{2}(9-\theta \xi)\right]} \\
\bar{f}=\frac{D(1-\theta \xi)[\theta \xi(2 k-\sigma)(k+\sigma)-4 \delta]}{\left[16 \delta-8 k^{2} \theta \xi-16 k \theta \xi \sigma-\sigma^{2}(9-\theta \xi)\right]^{2}}-\frac{\delta(1-\theta \xi)\left[2 \delta+\sigma^{2}(\theta \xi-1)\right][2 \delta+\theta \xi \sigma(k+\sigma)]^{2}}{2\left[8 \delta^{2}+4 \delta \sigma^{2}(\theta \xi-1)+\theta \xi \sigma^{2}(\theta \xi-1)(k+\sigma)^{2}\right]^{2}}
\end{gathered}
$$

When $f$ satisfies $f^{*} \in(\max (0, \underline{f}), \bar{f})$, both the retailer's and manufacturer's profits will increase. From our comprehensive analysis, we conclude that when the dual-channel system achieves dual supply chain coordination in the form of $\left(\beta^{*}, f^{*}\right)$, the members and overall profits of the supply chain will improve, which will mitigate channel conflict, improve the operational efficiency of the dual-channel supply chain and maintain the dual-channel supply chain's balanced development.

\subsection{Numerical Analysis}

Because the result is too technically complex to conduct a generality analysis, we employ numerical simulations to study the action mechanism. Thus, we assume that $k=0.4, \sigma=0.6, \delta=2, \theta=0.6, \xi=0.8$, and focus on verifying the feasibility of the dual coordination mechanism of the dual-channel supply chain.

(1) Numerical analysis of total supply chain profit

By substituting the parameters into the above model, we can obtain the total profit of the supply chain under different coordination strategies as shown in Figure 2.

Figure 2 shows that when the cost sharing ratio is $\beta \in(0,0.72)$, i.e., the physical retailer needs to share $\beta \in(0,0.72)$, the total supply chain profit under the dual coordinated strategy is greater than the total supply chain profit under the uncoordinated strategy. The left boundary of the manufacturer's cost-sharing ratio is zero, indicating that the total profit of the supply chain can be increased as long as the manufacturer and retailer sign a contract. Optimal cost-sharing ratio $\beta$ maximizes the profit of the supply chain. Thus, the cost-sharing contract has better coordination utility, which is consistent with corollary 4 . 


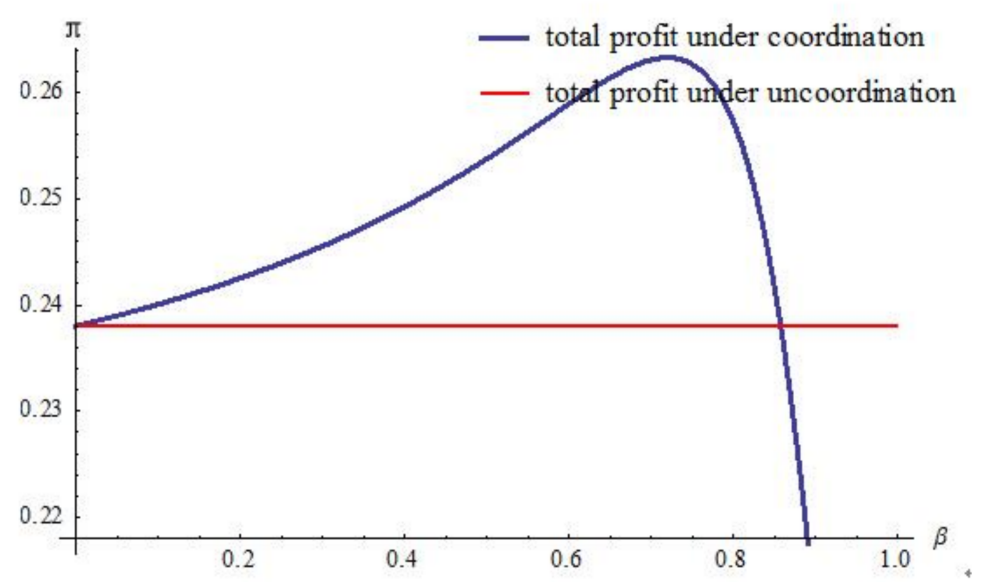

Figure 2. Total supply chain profit under different strategies.

(2) Numerical analysis of fixed subsidies

Through analysis, we obtain a trend plot of the range of fixed compensation for different values of parameter $\mathrm{f}$ as shown in Figure 3, where it is nonexistent when $f<0$.

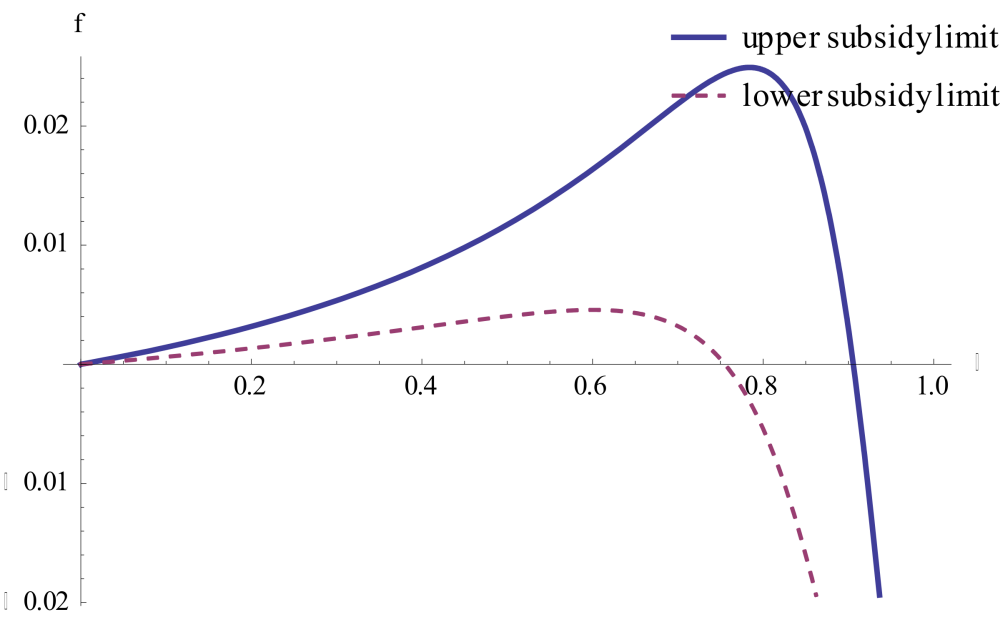

Figure 3. Fixed subsidy thresholds for different cost-sharing ratios.

Figure 3 shows an optimal interval between the fixed compensation received by the manufacturer, i.e., there is upper subsidy $\operatorname{limit} \bar{f}>0$ and lower subsidy limit $f>0$. In the optimal compensation interval, both the retailers' and manufacturers' profits are greater than those under the uncoordinated strategy, which means that the dual-channel coordination model with fixed compensation is effective in coordinating channel conflicts. Figure 3 shows that the upper limit of fixed compensation tends to increase first and then decrease as the proportion of sharing increases. As the proportion of the cost of innovation shared by the manufacturer increases, the retailer can effectively incentivize the manufacturer to share the cost of innovation by providing more subsidies. However, when the fixed subsidy exceeds the benefits of innovation, the retailer's profits and enthusiasm for cooperation are reduced, causing the fixed compensation to decrease.

The above analysis shows that the coordination strategy can simultaneously improve the profits of the retailer, manufacturer and supply chain when the innovation cost-sharing ratio and manufacturer's fixed compensation interval requirements are met. Compared to a single cost-sharing contract, revenue-sharing contract, etc., the cost-sharing ratio of the dual coordination mechanism shows a greater range of adjustment. In addition, contract elasticity between the manufacturer and retailer is greater. Therefore, the dual coordination 
mechanism can mitigate competition and conflict in the supply chain channel, which can improve the efficiency of supply chain operations and ultimately maintain the balanced development of the dual-channel supply chain.

\section{Discussions and Managerial Insights}

\subsection{Discussions}

In this paper, we constructed the cooperative and noncooperative supply chain Stackelberg game model based on the dual-channel structure and explored the complex mechanisms by which retailer innovation input levels affect the operation of the supply chain. According to Cho et al. [14] and Kim et al. [15], retailer innovation inputs can effectively coordinate channels, however, our study finds some distinct results by incorporating spillover effects into the game model. Depending on what we have achieved before, we will discuss what firms should do in practice to realize the system's best performance.

Both the manufacturer's and retailer's profits are a specific function of the level of investment in innovation. As is indicated in Proposition 2, 3 and 4, the level of innovation inputs offered by the retailer has an impact on the retailer's product pricing and online channel product pricing. The retailer will inevitably incur higher costs if increasing the level of innovation inputs. When the increase in the cost of innovation inputs is less than the increase in corresponding benefits, the retailer and manufacturer will aim to avoid a reduction in the total profitability of the supply chain by increasing the prices of their products.

As is shown in Corollary 1 , the retailer will focus on attracting consumers by providing innovation inputs, which imposes a higher cost, if the consumers' preferences for the online channel are lower. Hence, the retailer can appropriately increase the retail price of their products. In contrast, when consumers' preferences for the online channel are stronger, the retailer can use low prices to draw consumers toward physical channels. In general, noncooperation among channel members will affect offline prices, but the retailer can adjust pricing strategies appropriately according to consumers' online channel preferences.

Noncooperation among channel members affects the retailer's product pricing, decreases the market share of the physical channel and increases the market demand of manufacturers. As a result, manufacturers, as the dominant channel players, must actively join the retailer and strengthen cooperation among channel members to improve the operational efficiency and profitability of the channel, which is shown in Corollary 2. It is necessary to explore effective strategies for coordinating the dual channel to mitigate the impact of online channels on physical channels.

The dual coordination mechanism can alleviate channel conflicts, which can improve the operational efficiency of the supply chain. As is shown in Corollary 4 and Proposition 6 , the coordination strategy can simultaneously improve the profits of the retailer, manufacturer and supply chain when the innovation cost-sharing ratio and manufacturer's fixed compensation interval requirements are met. Compared to a single cost-sharing contract, revenue-sharing contract, etc., the cost-sharing ratio of the dual coordination mechanism shows a greater range of adjustment. In addition, contract elasticity between the manufacturer and retailer is greater.

The above analysis reveals that an optimal combination of wholesale prices, retail prices and innovation input levels can optimize the operational efficiency of the supply chain and improve its profitability. In addition, collaboration between supply chain members is critical for enterprises and supply chains. Therefore, it is necessary to explore effective strategies for coordinating the dual channel, which can improve the operational efficiency and optimize the profitability of the channel and maintain the balanced development of the dual-channel supply chain.

\subsection{Managerial Insights}

We consider the impact of retailer innovation investment spillover effect on channel competition and operational strategies, based on questions on consumers" "offline experi- 
ence, online purchase" shopping methods used in their daily lives. Afterwards, we propose the dual coordination contracts for channel conflicts. Results from the computational study provide several managerial insights for decision makers.

Firstly, these findings remind that the retailer can reduce the online channel's impact on the retailer channel through innovation inputs. Meanwhile, the retailer charges a high price and is more willing to invest in innovation when consumers have a particular preference for the retailer channel. Thus, supply chain enterprises, in reality, should make full use of consumer preference information when proposing channel strategies.

Secondly, our paper helps supply chain enterprises understand that competition between enterprises causes them to make decisions alone to maximize their respective profits rather than the total supply chain profit, resulting in a decline in total supply chain returns, which means cooperation among channel members benefits the supply chain while noncooperation harms the supply chain. Therefore, it is necessary to explore effective strategies for coordinating the dual channel to mitigate the impact of online channels on physical channels.

Thirdly, our research indicates that supply chain enterprises can charge high prices and benefit more from cooperation mechanisms. This mechanism implies a high innovation service level and leads to a large market share.

\section{Conclusions}

In this paper, we introduced the retailer's innovation inputs and spillover effects brought about by innovation into channel research, and developed a framework to study the effect of innovation investment on dual-channel supply chains. We examined the optimal decisions in cooperative and noncooperative supply chain Stackelberg game model based on consumer utility theory. We identified the action mechanisms of spillover effects and innovation inputs on channel pricing, channel competition and profit, then designed a cooperative mechanism designed to enhance the operational efficiency of the dual-channel supply chain.

The research provides a theoretical reference for supply chain pricing and coordination strategy, while having some limitations. The limitations are mainly reflected in the following aspects: First, we assumed that all information is known to be dual-channel and that market demand is certain. Therefore, we can expand on asymmetric information and uncertain market demand, considering information can be asymmetric and market demand can be uncertain. Second, we can use data analysis techniques to determine relevant parameters when constructing the model in the current context of big data, which can improve the accuracy of the model and make future research more meaningful. Furthermore, it is necessary to consider some forms of uncertainty, such as demand and information uncertainty, can also be considered.

Author Contributions: Conceptualization, W.Y. and Y.S.; methodology, Y.S.; software, Y.S. and J.Z.; validation, S.L., A.A. and Y.S.; formal analysis, Y.S.; investigation, Y.S.; resources, S.L.; data curation, Y.S.; writing—original draft preparation, Y.S. and W.Y.; writing—review and editing, S.L., A.A. and Y.S.; visualization, Y.S.; supervision, W.Y. and S.L.; project administration, Y.S.; funding acquisition, S.L., A.A. All authors contributed in joint research cooperation in the production of the manuscript, all authors made decisions and revisions together. They have read and agreed to the published version of the manuscript.

Funding: This research was funded by the National Natural Science Foundation of China under grant numbers 71771122 and 71862035; The Humanities and Social Sciences Foundation of the Ministry of Chinese Education under grant number 1151070862; The Jiangsu Philosophy and Social Science Foundation Project under grant number 19GLB009; The Yunnan Fundamental Research Project under grant number 2019FB085; The 21th Yunnan Young and Middle-aged Academic and Technical Leaders Reserve Personnel Training Program under grant number 2019HB030.

Institutional Review Board Statement: This study is not involving human or animals.

Informed Consent Statement: This study is not involving human. 
Data Availability Statement: All relevant data are within the paper.

Conflicts of Interest: The authors declare no conflict of interest.

\section{Appendix A. Proof of Proposition 1}

We obtained the Hessian matrix by finding the second-order partial derivatives of $\Pi^{c}$ with respect to $p_{r}^{c}, p_{e}^{c}$ and $s^{c}$ as follows:

$$
\begin{aligned}
& H\left(s^{c}, p_{r}^{c}, p_{e^{\prime}}^{c}\right)=\left[\begin{array}{ccc}
\frac{\partial_{\Pi^{c}}^{2}}{\partial s^{c 2}} & \frac{\partial_{\Pi^{c}}^{2}}{\partial s^{c} \partial p_{r}^{c}} & \frac{\partial_{\Pi^{c}}^{2}}{\partial s^{c} \partial p_{e}^{c}} \\
\frac{\partial_{\Pi^{c}}^{2}}{\partial p_{r}^{c} \partial s^{c}} & \frac{\partial_{\Pi^{c}}^{2}}{\partial p_{r}^{c 2}} & \frac{\partial_{\Pi^{c}}^{2}}{\partial p_{r}^{c} \partial p_{e}^{c}} \\
\frac{\partial_{\Pi^{c}}^{2}}{\partial p_{e}^{c} \partial s^{c}} & \frac{\partial_{\Pi^{c}}^{2}}{\partial p_{e}^{c} \partial p_{r}^{c}} & \frac{\partial_{\prod^{c}}^{2}}{\partial p_{e}^{c 2}}
\end{array}\right]=\left[\begin{array}{ccc}
-\delta & \sigma & k \\
\sigma & \frac{2}{-1+\theta \xi} & -\frac{2}{-1+\theta \xi} \\
k & -\frac{2}{-1+\theta \xi} & -\frac{2}{\theta \xi-\theta^{2} \xi^{2}}
\end{array}\right] \quad \text { (A1) } \\
& \text { Because } \frac{\partial_{\Pi^{c}}^{2}}{\partial p_{r}^{2}}=\frac{2}{-1+\theta \xi}<0 \text { and }\left[\begin{array}{cc}
\frac{2}{-1+\theta \xi} & -\frac{2}{-1+\theta \xi} \\
-\frac{2}{-1+\theta \xi} & -\frac{2}{\theta \xi-\theta^{2} \xi^{2}}
\end{array}\right]=\frac{4}{(1-\theta \xi)^{2}}\left(\frac{1}{\theta \xi}-1\right)>0,
\end{aligned}
$$

it is clear that $\Pi^{c}$ is a strictly concave function with respect to $p_{r}^{c}, p_{e}^{c}$. Similarly, since $\frac{\partial_{\Pi^{c}}^{2}}{\partial s^{2}}=-\delta<0$ and $\left[\begin{array}{cc}-\delta & \sigma \\ \sigma & \frac{2}{-1+\theta \xi}\end{array}\right]=\sigma^{2}-\frac{2 \delta}{(1-\varepsilon \theta)}$, it can be guaranteed to be greater than zero if and only if $\sigma^{2}>\frac{2 \delta}{(1-\varepsilon \theta)}$, but it is difficult to determine the concavity of $\Pi^{c}$ with respect to $s^{c}, p_{r}^{c}$, so it is clear that $\Pi^{c}$ is not a strictly concave function with respect to $p_{r}^{c}, p_{e}^{c}$ and $s^{c}$. The analysis results show that it is difficult to obtain the optimal solutions of $p_{r}^{c}, p_{e}^{c}$ and $s^{c}$ from the first-order conditions alone. First, given $s^{c}$, we apply the first-order optimality condition to obtain the optimal reaction function of $p_{r}^{c}$ and $p_{e}^{c}$.

$$
\left\{\begin{array}{l}
p_{r}^{c}=\frac{1}{2}\left(1+k s^{c} \theta \tilde{\zeta}+s^{c} \sigma\right) \\
p_{e}^{c}=\frac{\theta \zeta}{2}\left[1+s^{c}(k+\sigma)\right]
\end{array}\right.
$$

Second, we substitute $p_{r}^{c}, p_{e}^{c}$ into the revenue function and find the first-order derivative of $\Pi^{c}$ with respect to $s^{c}$ and make it zero. Then, the retailer's optimal innovation input level $s^{c}$ is

$$
\mathrm{s}^{\mathrm{c} *}=\frac{k \theta \xi+\sigma}{2 \delta-k^{2} \theta \xi-2 k \theta \xi \sigma-\sigma^{2}}
$$

According to the retailer's optimal innovation input level $s^{c *}$, we obtain optimal prices $p_{r}^{c *}, p_{e}^{c *}$ for the cooperative scenario. Then, we substitute $p_{r}^{c *}, p_{e}^{c *}$ and $s^{c *}$ into Equation (3). Finally, we obtain the optimal profit of the supply chain $\Pi^{c *}$.

\section{Appendix B. Proof of Proposition 5}

Based on the two-stage game process, the inverse induction method is used to solve the problem. In solving the first-order conditions of $\Pi_{r}^{D}$, we obtain the following equation:

First, we prove that $\prod_{r}^{D}$ is a strictly concave function of $p_{r}^{D}, s^{D}$ by the Hessen matrix. Then, we derive the first-order derivative of $\prod_{r}^{D}$ with respect to $p_{r}^{D}, s^{D}$ and make it zero. We can then obtain the retailer's reaction function.

$$
\left\{\begin{array}{l}
p_{r}^{D}=\frac{p_{w}^{D}\left[2 \delta+(\theta \xi-1) \sigma^{2}\right]+\delta\left(1+p_{e}^{D}-p_{w}^{D}-\theta \xi\right)}{2 \delta+(\theta \xi-1) \sigma^{2}} \\
s^{D}=\frac{\left(1+p_{e}^{D}-p_{w}^{D}-\theta \xi\right) \sigma}{2 \delta+(\theta \xi-1) \sigma^{2}}
\end{array}\right.
$$

Second, we bring $p_{r}^{D}$ and $s^{D}$ into the manufacturer's profit function; then, it can be determined that $\prod_{m}^{D}$ is a strictly concave function of $p_{w}^{D}$ and $p_{e}^{D}$. Next, we find first- 
order derivative $\prod_{m}^{D}$ with respect to $p_{w}^{D}, p_{e}^{D}$ and make it zero, the manufacturer's optimal decisions $p_{w}^{D *}$ and $p_{e}^{D *}$ can then be obtained as shown in Equation (A5).

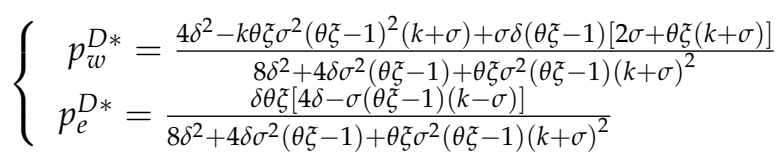

Then, we substitute Equation (A5) into Equation (A4), and the optimal $p_{r}^{D *}$ and $s^{D *}$ can then be obtained as shown in Equation (A6).

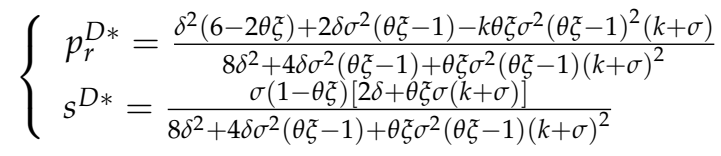

Finally, we substitute Equations (A5) and (A6) into Equation (5), and the optimal $\prod_{m}^{D *}, \prod_{r}^{D *}$ and $\Pi^{D *}$ can then be obtained as shown in Equation (8).

\section{Appendix C. Proof of Proposition 9}

Based on the two-stage game process, the inverse induction method is used to solve the problem. In solving the first-order conditions of $\prod_{m}^{I}$, we obtain the following equation:

First, we derive the first-order partial derivative with respect to $p_{r}^{I}$ and $s^{I}$ for $\prod_{m}^{I}$ and make it equal to 0. Thus, we obtain the retailer's reaction function as shown in Equation (A7).

$$
\left\{\begin{array}{l}
p_{r}^{I}=\frac{(\beta-1) \delta\left(1+p_{e}^{I}+p_{w}^{I}-\theta \xi\right)+p_{w}^{I}(1-\theta \xi) \sigma^{2}}{2(1-\beta) \delta+(\theta \xi-1) \sigma^{2}} \\
s^{I}=\frac{\left(1+p_{e}^{I}-p_{w}^{I}-\theta \xi\right) \sigma}{2(1-\beta) \delta+(\theta \zeta-1) \sigma^{2}}
\end{array}\right.
$$

Second, we substitute $p_{r}^{I}, s^{I}$ into the manufacturer's profit function. Then, it can be determined that $\prod_{m}^{I}$ is a strictly concave function about $p_{w}^{I}, p_{e}^{I}$ and $s^{I}$. Furthermore, we can obtain the manufacturer's optimal decisions $p_{w}^{D *}, p_{e}^{D *}$ and $s^{I *}$ when making them zero.

$$
\left\{\begin{array}{c}
p_{w}^{I *}=\frac{16 \delta-(1-\theta \xi)\left[8 k^{2} \theta \xi+6 k \theta \xi \sigma+\sigma^{2}(6+\theta \xi)\right]}{2\left[16-8 k^{2} k^{\xi}-16 k \theta \xi \sigma-\sigma^{2}(9-\theta \xi)\right]} \\
p_{e}^{I *}=\frac{\theta \zeta[16 \delta+3 \sigma(1-\theta \xi)(2 k-\sigma)]}{2\left[16 \delta-8 k^{2} \theta \xi-16 k \theta \xi \sigma-\sigma^{2}(9-\theta \xi)\right]} \\
\beta^{*}=\frac{8 k \delta \theta \xi+2\left[\delta+3 \delta \theta \xi+k^{2} \theta \xi(1-\theta \xi)\right] \sigma+k \theta \xi \sigma^{2}(1-\theta \xi)-\theta \zeta \sigma^{3}(1-\theta \xi)}{2 \delta[3 \sigma+\theta \xi(4 k+\sigma)]}
\end{array}\right.
$$

Then, by substituting Equation (A8) into Equation (A7), the optimal $p_{r}^{I *}$ and $s^{I *}$ can be obtained as shown in Equation (A9).

$$
\left\{\begin{array}{l}
p_{r}^{I *}=\frac{8 \delta(3-\theta \xi)-(1-\theta \xi)\left[12 k^{2} \theta \xi+8 k \theta \xi \sigma+\sigma^{2}(6-\theta \xi)\right]}{2\left[16 \delta-8 k^{2} \theta \xi-16 k \theta \xi \tau-\sigma^{2}(9-\theta \xi)\right]} \\
S^{I *}=\frac{6 \sigma+2 \theta \zeta(4 k+\sigma)}{16 \delta-8 k^{2} \theta \xi-16 k \theta \xi \zeta-\sigma^{2}(9-\theta \xi)}
\end{array}\right.
$$

Finally, we substitute Equations (A8) and (A9) into Equation (9), and the optimal $\prod_{m}^{I *}, \prod_{r}^{I *}$ and $\prod^{I *}$ can be obtained as shown in Equation (12).

\section{References}

1. Sherafati, M.; Bashiri, M.; Tavakkoli-Moghaddam, R.; Pishvaee, M.S. Achieving sustainable development of supply chain by incorporating various carbon regulatory mechanisms. Transp. Res. Part D Transp. Environ. 2020, 81, 102253. [CrossRef]

2. Deng, W.; Feng, L.; Zhao, X.; Lou, Y. Effects of supply chain competition on firms' product sustainability strategy. J. Clean. Prod. 2020, 275, 124061. [CrossRef]

3. Ryu, M.H.; Cho, Y.; Lee, D. Should small-scale online retailers diversify distribution channels into offline channels? Focused on the clothing and fashion industry. J. Retail Consum. Serv. 2019, 47, 74-77. [CrossRef]

4. Liu, L.; Feng, L.; Xu, B.; Deng, W. Operation strategies for an omni-channel supply chain: Who is better off taking on the online channel and offline service? Electron. Commer. Res. Appl. 2020, 39, 100918. [CrossRef] 
5. Zhang, P.; Xiong, Y.; Xiong, Z. Coordination of a dual-channel supply chain after demand or production cost disruptions. Int. J. Prod. Res. 2014, 53, 3141-3160. [CrossRef]

6. Chiang, W.K.; Chhajed, D.; Hess, J.D. Direct Marketing, Indirect Profits: A Strategic Analysis of Dual-Channel Supply-Chain Design. Manag. Sci. 2003, 49, 1-20. [CrossRef]

7. Du, Y.; Cui, M.; Su, J. Implementation processes of online and offline channel conflict management strategies in manufacturing enterprises: A resource orchestration perspective. Int. J. Inf. Manag. 2018, 39, 136-145. [CrossRef]

8. Lu, J.; Yang, Y.; Han, S.; Tsao, Y.; Xin, Y. Coordinated inventory policies for meeting demands from both store and online BOPS channels. Comput. Ind. Eng. 2020, 145, 106542. [CrossRef]

9. Liu, Z.; Wu, F.; Ren, X. Research on Different Pricing Strategy in Dual Channel under the Circumstance of Electronic Commerce. Int. J. Multimed. Ubiquitous Eng. 2014, 9, 301-314. [CrossRef]

10. Shaban, A.; Shalaby, M.A.; Di Gravio, G.; Patriarca, R. Analysis of Variance Amplification and Service Level in a Supply Chain with Correlated Demand. Sustainability 2020, 12, 6470. [CrossRef]

11. May, A.D. Urban Transport and Sustainability: The Key Challenges. Int. J. Sustain. Transp. 2013, 7, 170-185. [CrossRef]

12. Zimon, D.; Tyan, J.; Sroufe, R. Implementing Sustainable Supply Chain Management: Reactive, Cooperative, and Dynamic Models. Sustainability 2019, 11, 7227. [CrossRef]

13. Zimon, D.; Tyan, J.; Sroufe, R. Drivers of sustainable supply chain management: Practices to alignment with un sustainable development goals. Int. J. Qual. Res. 2020, 14, 219-236. [CrossRef]

14. Cho, R.K.; Gerchak, Y. Supply chain coordination with downstream operating costs: Coordination and investment to improve downstream operating efficiency. Eur. J. Oper. Res. 2005, 162, 762-772. [CrossRef]

15. Kim, B. Coordinating an innovation in supply chain management. Eur. J. Oper. Res. 2005, 123, 568-584. [CrossRef]

16. Shen, Y. A Production Inventory Model for Deteriorating Items with Collaborative Preservation Technology Investment Under Carbon Tax. Sustainability 2019, 11, 5027. [CrossRef]

17. Telser, L.G. Why should manufacturers want fair trade? J. Law Econ. 1960, 3, 86-105. [CrossRef]

18. Perry, M.K.; Porter, R.H. Can resale price maintenance and franchise fees correct sub-optimal levels of retail service? Int. J. Ind. Organ. 1990, 8, 115-141. [CrossRef]

19. Wang, Y.; Jia, F.; Schoenherr, T.; Gong, Y. Supply Chain-Based Business Model Innovation: The Case of a Cross-Border E-Commerce Company. Sustainability 2018, 10, 4362. [CrossRef]

20. Zhou, H.; Gu, X.; Li, L. The dynamic investment strategy of online advertising based on spillover effect in duopoly competition market. Computing 2018, 100, 881-905. [CrossRef]

21. Gao, D.; Xu, Z.; Ruan, Y.Z.; Lu, H. From a systematic literature review to integrated definition for sustainable supply chain innovation (SSCI). J. Clean. Prod. 2017, 142, 1518-1538. [CrossRef]

22. Tebaldi, L.; Bigliardi, B.; Bottani, E. Sustainable Supply Chain and Innovation: A Review of the Recent Literature. Sustainability 2018, 10, 1-29. [CrossRef]

23. Liu, B.; Yang, G.; Zhang, Q. Pricing Decisions and Innovation Strategies Choice in Supply Chain with Competing Manufacturers and Common Supplier. Sustainability 2020, 12, 8855. [CrossRef]

24. Guangwen, K.; Rajagopalan, S.; Hao, Z. Revenue Sharing and Information Leakage in a Supply Chain. Management 2013, 59, 556-572.

25. Wu, D.; Chen, J.; Li, P.; Zhang, R. Contract coordination of dual channel reverse supply chain considering service level. J. Clean. Prod. 2020, 260, 121071. [CrossRef]

26. Ranjan, A.; Jha, J.K. Pricing and coordination strategies of a dual-channel supply chain considering green quality and sales effort. J. Clean. Prod. 2019, 218, 409-424. [CrossRef]

27. Xu, X.; Zhang, M.; He, P. Coordination of a supply chain with online platform considering delivery time decision. Transp. Res. Part E Logist. Transp. Rev. 2020, 141, 101990. [CrossRef]

28. Feng, L.; Govindan, K.; Li, C. Strategic planning: Design and coordination for dual-recycling channel reverse supply chain considering consumer behavior. Eur. J. Oper. Res. 2017, 260, 601-612. [CrossRef]

29. Hosseini-Motlagh, S.; Nouri-Harzvili, M.; Choi, T.; Ebrahimi, S. Reverse supply chain systems optimization with dual channel and demand disruptions: Sustainability, CSR investment and pricing coordination. Inf. Sci. 2019, 503, 606-634. [CrossRef]

30. Aslani, A.; Heydari, J. Transshipment contract for coordination of a green dual-channel supply chain under channel disruption. $J$. Clean. Prod. 2019, 223, 596-609. [CrossRef]

31. Li, Z.; Yang, W.; Liu, X.; Si, Y. Coupon promotion and its two-stage price intervention on dual-channel supply chain. Comput. Ind. Eng. 2020, 145, 106543. [CrossRef]

32. Sankaranarayanan, R. Innovation and the Durable Goods Monopolist: The Optimality of Frequent New-Version Releases. Mark. Sci. 2007, 26, 774-791. [CrossRef]

33. Gil-Molto, M.J.; Poyago-Theotoky, J.; Zikos, V. R \& D Subsidies, Spillovers, and Privatization in Mixed Markets. South Econ. J. 2011, 78, 233.

34. Battistella, C.; Biotto, G.; De Toni, A.F. From design driven innovation to meaning strategy. Manag. Decis. 2012, 50, 718-743. [CrossRef]

35. Jian, X.; Bin, D.; Xu-mei, Z. Service cooperation pricing strategy between manufacturers and retailers in dual-channel supply chain. Syst. Eng. Theory Pract. 2010, 30, 2203-2211. 
36. Giri, B.C.; Roy, B. Dual-channel competition: The impact of pricing strategies, sales effort and market share. Int. J. Manag. Sci. Eng. Manag. 2015, 11, 203. [CrossRef]

37. Song, J.; Li, F.; Wu, D.D.; Liang, L.; Dolgui, A. Supply chain coordination through integration of innovation effort and advertising support. Appl. Math. Model 2017, 49, 108-123. [CrossRef]

38. Carlton, D.W.; Chevalier, J.A. Free Riding and Sales Strategies for the Internet. J. Ind. Econ. 2001, 49, 441-461. [CrossRef]

39. Wu, D.; Ray, G.; Geng, X.; Whinston, A. Implications of Reduced Search Cost and Free Riding in E-Commerce. Mark. Sci. 2004, 23, 255-262. [CrossRef]

40. Shin, J. How Does Free Riding on Customer Service Affect Competition? Mark. Sci. 2007, 26, 488-503. [CrossRef]

41. Bernstein, F.; Song, J.; Zheng, X. Free riding in a multi-channel supply chain. Nav. Res. Logist. 2009, 56, 745-765. [CrossRef]

42. Cai, G.G.; Zhang, Z.G.; Zhang, M. Game theoretical perspectives on dual-channel supply chain competition with price discounts and pricing schemes. Int. J. Prod. Econ. 2009, 117, 80-96. [CrossRef]

43. Chen, K.; Kaya, M.; Özer, Ö. Dual Sales Channel Management with Service Competition. Manuf. Serv. Oper. Manag. 2008, 10, 654-675. [CrossRef]

44. Dan, B.; Xu, G.; Liu, C. Pricing policies in a dual-channel supply chain with retail services. Int. J. Prod. Econ. 2012, 139, 312-320. [CrossRef]

45. Zhang, J.; He, X. Targeted advertising by asymmetric firms. Omega 2019, 89, 136-150. [CrossRef]

46. Chen, Y.; Narasimhan, C.; Zhang, Z.J. Individual Marketing with Imperfect Targetability. Mark. Sci. 2001, 20, 23-41. [CrossRef]

47. Zong-huo, L.I.; Wen-sheng, Y.; Xin-tong, C. Coordination strategy based on retailer innovative input in dual-channel supply chains. Control Decis. 2019, 34, 1754-1760. 